\title{
THE SPECIFIC PRECIPITIN REACTION OF THE NORMAL AND CATARACTOUS LENS
}

\author{
LUDVIG HEKTOEN \\ From the John McCormick Institute for Infectious Diseases, Chicago
}

In this article are recorded briefly the results of experiments on the precipitin reaction of the lens, ${ }^{1}$ with special reference to the human lens in senile cataract.

It is a remarkable fact, discovered by Uhlenhuth and verified by others, ${ }^{2}$ that the lens of different species contains identical antigenic elements. A lens antiserum produced by injecting a rabbit or guineapig with beef lens reacts in precipitation, anaphylaxis and fixation tests not only with beef lens but also with the lens of other mammals, of birds and amphibians. With fish lens the precipitin reaction, however, is faint. The specificness of the reaction is limited not by species as in the immune reactions of blood, of serum proteins, and of bacteria, but by the organ from which the antigen is derived.

I have studied the precipitins that develop in rabbits on the injection of lens solutions in $0.9 \%$ salt solution. The principal experiments have been made with approximately 5 or $10 \%$ solutions by weight of beef, horse, rabbit, sheep and swine lens, removed with special care to avoid admixture with blood or serum, and with approximately $2.5 \%$ solutions of human lens, the seat of senile cataract. The preliminary tests of cataractous material were made with 5 lenses from the Cook County Hospital (Dr. E. V. L. Brown). The 50 cataractous lenses in table 1 were obtained from the Illinois Charitable Eye and Ear Infirmary (Dr. E. K. Findlay). In all cases the solutions of lens substances have been made by shaking lenses with glass beads in $0.9 \%$ salt solution. The strength of the resulting solutions is based on the weight of the original lens, and as the amount of insoluble residue varies greatly, especially in cataractous lenses, the strengths of the lens solutions given in this article are as a rule approximate only. For injections and tests absolutely clear lens solutions have been used. In some cases the lens solutions were passed through Berkefeld filters in order to insure sterility. Four

Received for publication April 1, 1922.

1 A brief report of the observations on the precipitin reactions of the normal lens appeared in Jour. Am. Med. Assn., 1921, 77, p. 32, and Trans, Chicago Path. Soc., 1921, 11 , p. 221 .

2 The literature is reviewed by Kodama, Jour. Infect. Dis, 1922, 30, p. 418. 
or 5 injections have been given intravenously at 3 or 4 day intervals, first of 2 to $4 \mathrm{cc}$ of solution, increasing gradually to between 12 and $16 \mathrm{cc}$ the last time. It must be remembered that in all cases the lens solutions used for immunizing injections were made either by shaking several lenses in the same quantity of salt solution or by mixing the solutions of many single lenses as was done in the case of the cataractous lenses. The highest precipitin titer appears to be reached about the seventh or the eighth day after the last injection. Contrary to the experience of Uhlenhuth, it does not seem to be very difficult to obtain

TABLE 1

Prectpitis Reactions of the Normal and Cataractous lens

\begin{tabular}{|c|c|c|c|c|c|c|c|c|c|c|c|}
\hline \multirow[b]{2}{*}{ Lenses } & \multicolumn{5}{|c|}{ Lens Antiserums } & \multicolumn{5}{|c|}{ Serum Antiserums } & \multirow{2}{*}{$\begin{array}{l}\text { Nor- } \\
\text { mal } \\
\text { Rab- } \\
\text { bit } \\
\text { Serum }\end{array}$} \\
\hline & Beef & Horse & $\left|\begin{array}{c}\text { Human } \\
\text { Catar- } \\
\text { actous } \\
\text { Lens }\end{array}\right|$ & Sheep & Swine & Beef & Horse & Sheep & Swine & Human & \\
\hline Beef Jens.............. & + & + & + & + & + & 0 & 0 & 0 & 0 & 0 & $\theta$ \\
\hline Ohicken lens.......... & + & + & + & + & + & 0 & 0 & 0 & 0 & 0 & 0 \\
\hline Dog lens................ & + & + & + & + & + & 0 & 0 & 0 & 0 & 0 & 0 \\
\hline Guinea-pig lens...... & + & + & + & + & + & 0 & 0 & 0 & 0 & 0 & 0 \\
\hline Horse lens............ & + & + & + & + & + & 0 & 0 & 0 & 0 & 0 & 0 \\
\hline Human lens, normal & + & + & + & + & + & 0 & 0 & 0 & 0 & 0 & 0 \\
\hline 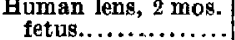 & + & $t$ & + & + & + & 0 & 0 & 0 & 0 & OR & 0 \\
\hline Monkey lens.......... & + & + & + & $\begin{array}{l}+ \\
+\end{array}$ & + & $\begin{array}{l}u \\
0\end{array}$ & 0 & 0 & 0 & 0 & 0 \\
\hline Rabbit lens........... & + & + & + & + & + & 0 & 0 & 0 & 0 & 0 & 0 \\
\hline Rat lens.............. & + & + & + & + & + & 0 & 0 & 0 & 0 & 0 & 0 \\
\hline Sheep lens............. & + & + & + & + & + & 0 & 0 & 0 & 0 & (t) & 0 \\
\hline Swine lens............. & $t$ & + & + & $t$ & + & 0 & 0 & 0 & 0 & 0 & 0 \\
\hline $\begin{array}{l}\text { Human lens, senile } \\
\text { cataract, } 50 \text { lenses }\end{array}$ & & & & & & & & & & & \\
\hline tested separately.. & + & + & + & + & + & 0 & 0 & 0 & 0 & 0 & 0 \\
\hline Beef serum....... & 0 & 0 & 0 & 0 & 0 & + & \pm & + & 0 & 0 & 0 \\
\hline Horge gerum......... & 0 & 0 & 0 & 0 & 0 & \pm & $\bar{t}$ & 0 & 0 & 0 & 0 \\
\hline Human serum........ & 0 & 0 & 0 & 0 & 0 & $\overline{0}$ & \pm & 0 & 0 & + & 0 \\
\hline $\bar{M}$ onkey serum........ & 0 & 0 & 0 & 0 & 0 & 0 & $\overline{0}$ & 0 & 0 & \pm & 0 \\
\hline Sheep serum .......... & 0 & 0 & 0 & 0 & 0 & + & 0 & + & 0 & $\overline{0}$ & 0 \\
\hline Swine serum.......... & 0 & 0 & 0 & 0 & 0 & \pm & \pm & \pm & + & 0 & 0 \\
\hline Rabbit serum......... & 0 & 0 & 0 & 0 & 0 & 0 & 0 & 0 & 0 & 0 & 0 \\
\hline
\end{tabular}

All lens antiserums produced by injecting mixed solutions of different lenses of the same kind and active in all normal lens dilutions of $1: 5,000$ at least.

Serum antiserumg active in homologous serum diluted from $1: 4,000$ to $1: 12,000$. In some cases these antiserums react with the serum of related species.

+ , strong reaction; \pm slight reaction; 0 , no reaction.

strong antiserums, and all the tests tabulated were made with serums that would cause precipitates in dilutions of normal lens of at least $1: 5,000$ and usually much higher in some cases as high as $1: 240,000$.

The tests have been made by the contact method and the results read after one hour at room temperature. Table 1 shows that all the lens solutions (beef, chicken, dog, guinea-pig, horse, human, monkey, rabbit, rat, sheep, swine) reacted in the same general way with beef, horse, sheep, swine and cataractous (human) lens antiserums; further, 
that none of these lens antiserums reacted with the blood serum of either the corresponding or any of the other species represented, and conversely, that no serum antiserum reacted with any lens solution. In order to be sure that the failure to react in no case was merely apparent and due to the so-called prozone inhibition, the tests of the blood serums with antilens serums and of lens solutions with the serum antiserums were carried out in a series of progressive dilutions of all the antigens far beyond the range of prozone action.

The antilens serums tabulated had no action on extracts of any other human organs than the lens. The extracts were made by grinding finely divided pieces of the various organs with quartz sand in salt solution and then shaking thoroughly, the strength of each extract being one part organ in four parts salt solution.

TABLE 2

Comparison of Actions of Antiheghens and Anticataract Serums on Same. Lens Solutions

\begin{tabular}{|c|c|c|}
\hline Lens Solutions & $\begin{array}{l}\text { Antibeeflens } \\
\text { Serum }\end{array}$ & $\begin{array}{l}\text { Anticataract } \\
\text { Serum }\end{array}$ \\
\hline 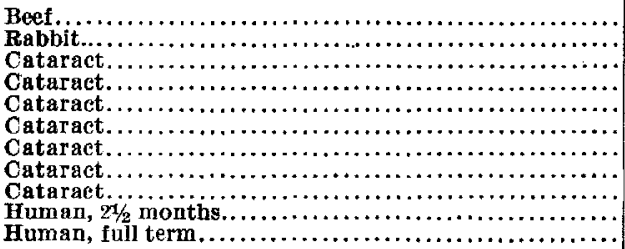 & $\begin{array}{r}240,000 \\
160,000 \\
1,600 \\
12,800 \\
6,400 \\
200 \\
3,200 \\
1,600 \\
1,600 \\
3,200 \\
1,280\end{array}$ & $\begin{array}{r}240,000 \\
160,000 \\
50,000 \\
100,000 \\
100,000 \\
12,800 \\
24,000 \\
100,000 \\
50,000 \\
12,800 \\
80,000\end{array}$ \\
\hline
\end{tabular}

The figures give the highest dilutions of the lens solutions in which the antiserums caused definite precipitates by the ring or contact method after one hour at room temperature.

The cataractous lenses listed in table 1 were all tested with various antihuman serums produced by injecting rabbits with human serum, human serum globulins, Bence Jones proteins, and human serum albumin prepared in the usual way. In only 8 of the 50 lens solutions did reaction develop and only with the antialbumin serum and in low dilutions of the lens solutions. The antialbumin serum in question had no effect on solutions of human serum globulin.

Generally speaking, the cataractous lenses reacted in the same way to the different antilens serums but not always in the same degree. As a rule, the antiserums produced by injections of solutions of cataractous lenses gave reactions in higher dilutions of these solutions than did antiserum to beef lens for instance. Table 2 illustrates this point, and the results there recorded appear to indicate clearly that there are distinct 
differences between the antigens in beef lens and human lens of senile cataract or that the solutions of cataractous lenses may contain substances that inhibit the precipitin reaction of antiserum for beef lens. This statement seems applicable also to solutions of the fetal human lens. Several attempts were made by specific absorption methods to obtain indications of different precipitinogens in cataractous and beef lens solutions and of different precipitins in the respective antiserums, but invariably treatment of any lens antiserum with solutions of cataractous or other lens and of anticataract serum with solutions of beef or other lens resulted in the complete removal of all the antilens precipitins. So far then, no differences have been observed in the precipitin reactions that seem to point to a possible separation into distinct groups of the cataractous lenses, all of which were classed as examples of senile cataract by the ophthalmologists. Whether other and rarer forms of cataract are associated with more definite alterations in the precipitinogenic nature of the lens protein is an interesting question. To answer such questions with success it no doubt will be of great advantage to use antilens serums of as nearly monovalent or simple a nature as possible rather than the presumably more complex antiserums from injections of solutions of many different lenses probably containing a greater variety of more or less closely related antigens.

The absorption experiments referred to were made by mixing the antiserum in full strength with one or two volumes of lens solution, varying in strength from $1: 100$ to $1: 600$, leaving the mixtures at room temperature for an hour or two and then in the icebox over night. The precipitate that had formed was removed by centrifugation and the clear fluid tested. Similar experiments with lens antisertum and dilutions of normal serum have given negative results, that is, the lens precipitin was not removed.

The lenses of puppies 3 weeks old reacted like the lenses of adult dogs. Fetal human lenses from all stages (obtained from the Cook County Hospital through Dr. Willson B. Moody), the earliest being at about the end of the second month, all gave typical lens specific reactions, but in much higher dilutions with antiserums for human lens (cataractous) than with antiserums for beef lens, for instance, as shown in table 2, this result suggesting as stated already the presence in the fetal lens either of antigens that differ from those in the beef lens or of substances that inhibit the action of beeflens precipitin. Other possibilities may be suggested also. In two of the fetal human lenses ordinary antihuman serum showed the presence of species-specific 
proteins but only in small quantities, a result that appears to differ somewhat from that of Szily ${ }^{3}$ who found species-specific proteins in considerable quantities regularly in the embryonal chicken lens. No doubt a further study of the embryonal lens by means of the precipitin reaction would yield interesting results.

Extracts of beef retina, uvea, and cornea gave no reactions with strong antiserum for beef lens and the serums of rabbits injected with extracts of beef cornea and of beef uvea gave no precipitin reactions with beef lens or any of the other lenses, both these serums reacting strongly, however, with beef serum and extracts of beef cornea. The antiuveal serum reacted well with extract of beef uvea and retina also, but the anticornea serum was not tested with these extracts. These results invite further study with the precipitin reaction. As pointed out previously, ${ }^{1}$ the normal aqueous and vitreous humors, which contain species-specific antigens, may give a precipitin reaction with lens antiserum under conditions that seem to preclude the passage of this substance into the humors as the result of handling of the eye. The aqueous humor of the eye of a rabbit, from which the lens had been removed by the capsular method one month before (Dr. R. Kodama), gave a strong reaction with antiserums for beef and human lens. At present the significance of the occasional presence in the ocular humors of substances that react with antilens serum must remain unexplained. One fact stands out-the lens is much more strictly specific in its precipitin reactions, with reference to other eye tissues, than in its anaphylactic. reactions, as shown in the recent work of Kodama ${ }^{2}$.

The injection of strong antilens serum into the aqueous or vitreous in rabbits, after first withdrawing the proper quantity of humor, did not produce any peculiar or specific action on the lens.

In all cases the serum of rabbits containing lens precipitins, as the result of the injection of heterologous lens solutions, caused precipitates in solutions of rabbit lens in seemingly just as high dilution as in any other lens solution. Several rabbits have been injected many times intravenously and intramuscularly with solutions of rabbit lens, but lens precipitins could not be demonstrated in the serum. In other rabbits the injections of rabbit lens were associated with injections of sheep serum in order to put the antibody-forming mechanisms in motion, but no lens precipitins developed. In rabbits previously injected with beef or human lens, the injection of rabbit lens at a time when the

3 Klin. Monatsbl. f. Augenheilk,, 1921, 12, p. 150. 
precipitins from the first injections had disappeared from the blood almost completely, in one or two instances seemed to cause the production of small quantities of lens precipitins which, however, were lost quickly. In one rabbit previously injected with solution of human cataractous lens, in consequence of which it became for a time an active producer of lens precipitins, reinjection with solution of rabbit lens, which had been passed through a Berkefeld filter, was followed by a definite and well sustained new production of lens precipitins acting on solutions of rabbit as well as of other lenses. Contrary to the results of certain other investigators, Römer and Gebb ${ }^{4}$ as well as Morax and Pollack ${ }^{5}$ found that the guinea-pig reacted typically to the injection of guinea-pig lens only after sensitization with the lens of a different spccies. Similarly, rabbits, as a rule, appear to produce precipitins that react with rabbit lens as the result only of immunization with the lens of a different species. The problems presented by this form of "Horror autotoxius" challenge renewed attack. In connection with this matter, it is of great interest to note that Guyer ${ }^{6}$ after many attempts succeeded "in securing a defective-eyed young rabbit from a mother of normal stock by injecting her repeatedly with pulped rabbit lens before and during pregnancy."

\section{SUMMARY}

Precipitin tests of the lens of different species-beef, chicken, dog, guinea-pig, human (normal and cataractous), monkey, rabbit, rat, sheep, swine-with antiserums for beef, horse, human cataractous, sheep and swine lens, reveal a consistent organ-specificness in the precipitin reaction. The normal lens of these mammals gives no indications in the usual tests of containing any species-specific precipitinogens. This is true also of the lens of senile human cataract with the exception that 8 of 50 cataractous lenses gave a reaction for human serum albumin. In some cases the fetal human lens may contain species-specific elements.

The lens-specific elements in normal, cataractous and fetal lenses probably are not precipitinogenically identical, and it is possible that solutions of cataractous and other lenses contain substances that interfere with the action of heterologous antilens precipitins. Studies with momovalent or simple antilens serum may help to solve questions of this kind.

* Arch. f. Ophth., 1912, 81, p. 367.

5 Ann. de. l'Inst. Pasteur, 1914, 28, p. 625

B American Naturalist, 1921, 55, p. 97. 
The aqueous and vitreous humors sometimes may contain substances that react with antilens serum. Beef cornea, retina and uvea, however, do not appear to contain any precipitinogens in common with the lens.

Under ordinary circumstances rabbits produce precipitins that react freely with solutions of rabbit lens in response only to injections of lens of different species and not in response to injections of rabbit lens. Rabbits previously injected with foreign lens material, that is rabbits rendered allergic with respect to the lens, however, may respond to injection of solutions of rabbit lens with new production of lens precipitins which act on rabbit as well as other lens solutions. 